\title{
Abdominal obesity increases metabolic risk factors in non-obese adults: a Hungarian cross-sectional study
}

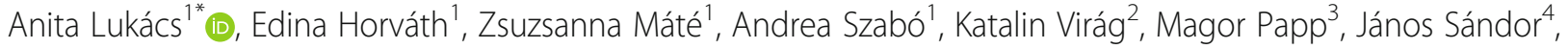 \\ Róza Ádány ${ }^{4,5}$ and Edit Paulik ${ }^{1}$
}

\begin{abstract}
Background: The prevalence of abdominal obesity is increasing worldwide. Adults with abdominal obesity have been reported to have increased risk of cardiometabolic disorders.

The aim of this study was to examine whether non-obese subjects (body mass index (BMI) $<25 \mathrm{~kg} / \mathrm{m}^{2}$ ) with abdominal obesity examined in the framework of the Swiss-Hungarian Cooperation Programme had increased metabolic risk compared to participants without abdominal obesity.

Methods: A cross-sectional study was carried out in 5228 non-obese individuals. Data were collected between July 2012 and February 2016. Descriptive statistics, Pearson's correlation analysis and multiple logistic regression models were applied, odds ratios (OR) with 95\% confidence interval (CI) being the outcomes.

Results: 607 (11.6\%) out of the 5228 non-obese individuals had abdominal obesity. The correlation analysis indicated that the correlation coefficients between BMI and waist circumference (WC) were 0.610 in males and 0.526 in females. In this subgroup, the prevalence of high systolic blood pressure, high fasting blood glucose, and high total cholesterol and triglyceride levels were significantly higher. The logistic regression model based on these data showed significantly higher risk for developing high systolic blood pressure $(\mathrm{OR}=1.53 ; 95 \% \mathrm{Cl}=1.20-1.94)$, low $\mathrm{HDL}$ cholesterol $(\mathrm{OR}=2.06 ; 95 \% \mathrm{Cl}=1.09-3.89)$, and high trygliceride level $(\mathrm{OR}=1.65 ; 95 \% \mathrm{Cl}=1.27-2.16)$.

Conclusions: There was a very high, significant, positive correlation between WC and BMI. Abdominal obesity was found to be strongly related to certain metabolic risk factors among non-obese subjects. Hence, measuring waist circumference could be recommended as a simple and efficient tool for screening abdominal obesity and related metabolic risk even in non-obese individuals.
\end{abstract}

Keywords: Abdominal obesity, Waist circumference, Metabolic syndrome, Prevention, Screening

\section{Background}

Obesity is one of the major public health concerns of our era: its prevalence has increased significantly in the past decades both globally $[1,2]$ and in Hungary $[3,4]$.

In Hungary, many people live with a high risk of metabolic syndrome, which promotes the development of atherosclerotic vascular diseases and type 2 diabetes mellitus (T2DM) [5], mainly due to abdominal obesity. The prevalence of the latter was $38 \%$ in males and $55 \%$

\footnotetext{
* Correspondence: lukacs.anita@med.u-szeged.hu

${ }^{1}$ Department of Public Health, Faculty of Medicine, University of Szeged,

Dóm tér 10, Szeged 6720, Hungary

Full list of author information is available at the end of the article
}

in females [6] in 2014, and the morbidity of T2DM has continuously been increasing [7]. Therefore, it is essential for heath professionals to be aware of the metabolic risk of this population.

Body mass index (BMI) is widely used to monitor the prevalence of obesity because the risk of coronary heart disease, ischemic stroke, and T2DM rises in parallel with the increase in the BMI [8]. Unfortunately, BMI provides limited information about body fat content and no information on central fat distribution, the degree of which may be more closely related to metabolic risks than BMI itself [9]. Body adiposity varies according to age and gender, and BMI alone is not appropriate to distinguish

(c) The Author(s). 2019 Open Access This article is distributed under the terms of the Creative Commons Attribution 4.0 International License (http://creativecommons.org/licenses/by/4.0/), which permits unrestricted use, distribution, and reproduction in any medium, provided you give appropriate credit to the original author(s) and the source, provide a link to the Creative Commons license, and indicate if changes were made. The Creative Commons Public Domain Dedication waiver (http://creativecommons.org/publicdomain/zero/1.0/) applies to the data made available in this article, unless otherwise stated. 
between persons with excess body fat and persons with high muscle mass, to whom the same metabolic risk would be attributed based purely on their BMI [10].

Nonetheless, several reports suggest that the measurement of waist circumference (WC) can compensate the above described limitation of BMI since WC is more closely related to visceral fat content, and thus to metabolic risks. Previous research shows that on the one hand, normal weight individuals with abdominal obesity can have metabolic risk factors, and therefore being candidates for having elevated risk for metabolic syndrome [11] or cardiovascular diseases (CVDs) [12], and on the other hand, measurements of abdominal obesity, principally WC, are more closely related to metabolic risk factors than the index of general adiposity [13]. According to Park et al. [10], WC as a marker of obesity is a better predictor of coronary artery calcification than BMI. Subjects with abdominal obesity were more likely to have a metabolic syndrome compared to those without abdominal obesity, therefore, WC should also be measured and used in conjunction with BMI to assess and predict metabolic risk, where possible, according to the conclusion of a recent report of the World Health Organization (WHO) [8].

There is, however, limited information about the usefulness of WC measurement in identifying cardiometabolic risk factors in a large study sample. Therefore, in our study, we aimed to examine whether non-obese subjects with no chronic conditions but abdominal obesity had a higher chance of having related metabolic risk factors, such as elevated blood pressure, high fasting blood glucose, high cholesterol, high low-density lipoprotein (LDL), low high-density lipoprotein (HDL), and high triglyceride levels, compared to persons with no abdominal obesity.

\section{Materials and Methods \\ Study design and subjects}

The programme, named 'Public Health Focused Model Programme for Organising Primary Care Services Backed by a Virtual Care Service Centre' (the Programme), has been an innovative health promotion and public health project, launched in July 2012 in Hungary in Swiss-Hungarian cooperation. The aim of the Programme was to provide efficient preventive services, contributing thereby to the improvement of the general health status of the population, and the reduction of social health inequality [14]. An element of the new services developed by the programme was the general practitioners' cluster (GPC) model (described elsewhere $[15,16])$, which was designed to establish a community-oriented screening system in Hungary with the aim of providing comprehensive evaluation of the health status of all adults above 18 years of age belonging to the GPCs, irrespective of their health status. The health check surveyed the sociodemographic status, lifestyle and health attitude (nutrition, physical activity, alcohol use, smoking), mental health, and history of chronic diseases and screenings for cardiometabolic risk factors and hidden diseases. The Health Status Assessment (HSA) was implemented by a team of a trained nurse and a trained public health practitioner [17], the task of who was to recruit the subjects, collect questionnaire-based data, and perform the physical and laboratory examinations.

It was a cross-sectional study conducted in adult persons taking part in the Programme, living in the two vulnerable regions of Hungary (located in the North Eastern part of the country). The target population comprised 32655 adults, and the health data of 20441 successfully recruited adult persons were recorded between July 2012 and February 2016. First, subjects who had hypertension, diabetes, ischemic heart disease, chronic obstructive pulmonary disease (COPD), and/or cancer were excluded. Then, further subjects were excluded because of the lack of their BMI and/or WC data, the characteristics of these 12520 Hungarian adult subjects are shown in Additional Table 1 (see Additional file 1). Finally, because of their high BMI $\left(\geq 25 \mathrm{~kg} / \mathrm{m}^{2}\right)$ scores, 7292 subjects were excluded. The final sample was formed by 5228 non-obese individuals, who were divided into two groups according to the WC. The two groups were formed based on the definition and thresholds - WC $>102 \mathrm{~cm}$ in men and WC $>88 \mathrm{~cm}$ in women - of Adult Treatment Panel III (ATP III), which presents the National Cholesterol Education Program's (NCEP's) updated recommendations for cholesterol testing and management [18]. There were 4621 persons in the group of normal WC (NWC), and 607 persons in the group of high WC (HWC) (Fig 1).

\section{Measurements}

The HSA involved a health interview, physical examination (performed by a public health practitioner and a community nurse), and laboratory tests. The data collected and the questions applied in the HSA are shown in Additional file 2 (see Additional file 2).

Based on the definition of metabolic syndrome [18], laboratory data of blood glucose, total cholesterol, LDL cholesterol, HDL cholesterol, and triglyceride levels were

Table 1 Normal ranges of laboratory parameters according to ATP III/WHO

\begin{tabular}{lll}
\hline Laboratory parameters & Normal Range & Organization \\
\hline Serum cholesterol & $<5.2 \mathrm{mmol} / \mathrm{L}$ & ATP III \\
Serum LDL cholesterol & $<2.6 \mathrm{mmol} / \mathrm{L}$ & ATP III \\
Serum HDL cholesterol & $\geq 1.0 \mathrm{mmol} / \mathrm{L}$ & ATP III \\
Serum triglyceride & $<1.7 \mathrm{mmol} / \mathrm{L}$ & ATP III \\
Fasting blood glucose level & $<6.1 \mathrm{mmol} / \mathrm{L}$ & WHO \\
\hline
\end{tabular}



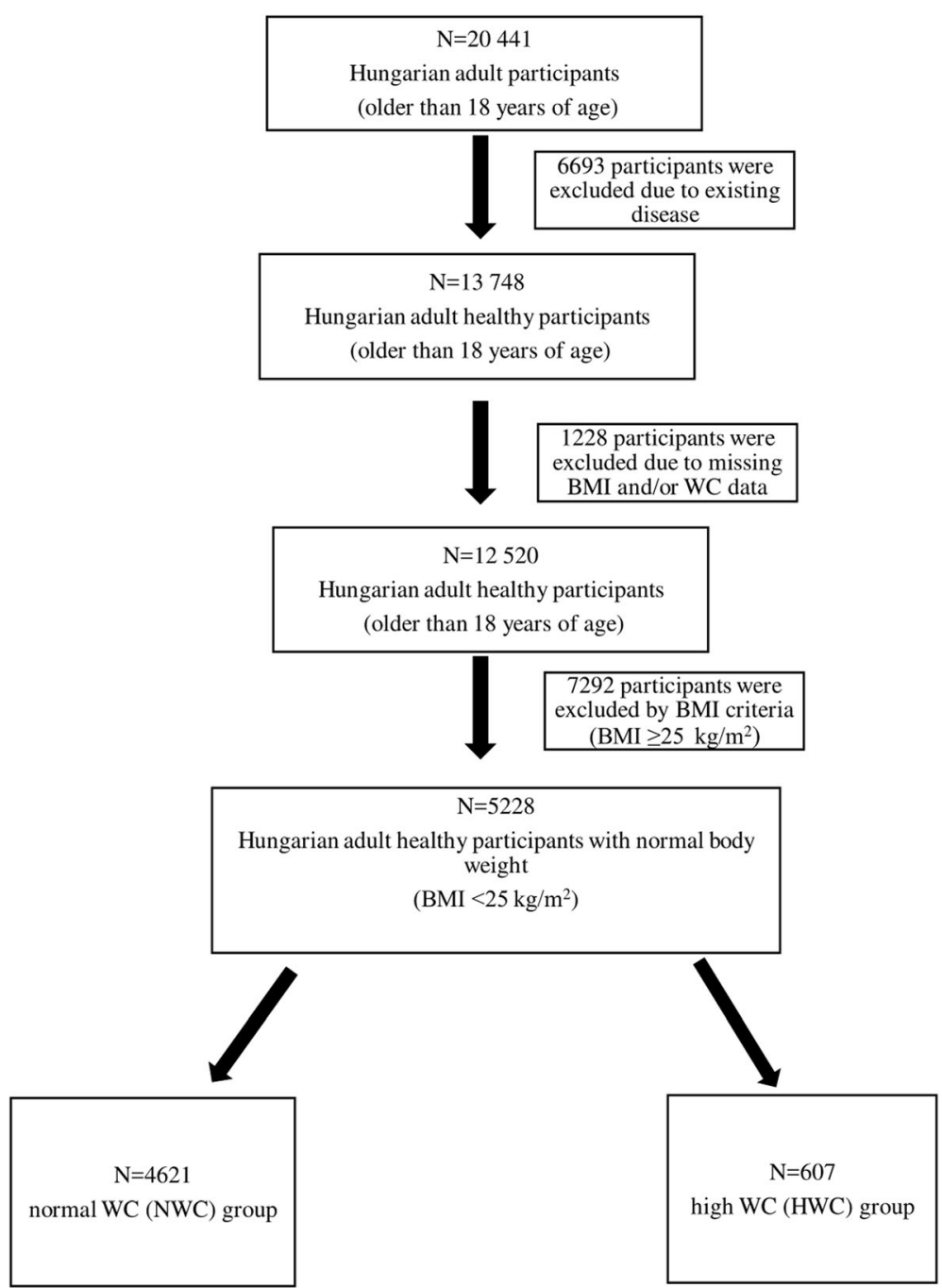

Fig. 1 Schematic diagram of the study sample. BMI: body mass index, WC: waist circumference

used. The thresholds for laboratory parameters given by the ATP III or the WHO [19] are shown in Table 1.

The public health professionals followed the WHO STEPS (STEPwise approach to surveillance) protocol to measure the WC, that is, the measurement is made at the approximate midpoint between the lowest rib and the iliac crest [20]. BMI was defined as the body weight divided by the square of the body height, and expressed in units of $\mathrm{kg} / \mathrm{m}^{2}$. Subjects with a BMI $<25 \mathrm{~kg} / \mathrm{m}^{2}$ were classified as non-obese, whereas those with BMI $\geq 25 \mathrm{~kg} /$ $\mathrm{m}^{2}$ were classified as obese according to the WHO definitions [21].

Blood pressure was measured by electronic blood pressure monitor after a five-minute rest. The classification of the American Heart Association, systolic blood pressure $\geq 140 \mathrm{mmHg}$ regarded as high blood pressure, was applied [22].

\section{Statistical analysis}

A chi-square test was performed to show the basic characteristics of the two groups. Pearson's correlation analysis was carried out to analyze the correlation between BMI and WC. A multiple logistic regression model was used to define the association between the metabolic risk factors and abdominal obesity with adjustments for age and gender. Metabolic risk factors were used as dependent variables, and abdominal obesity was defined as an independent variable. Odds ratios (OR) and 95\% confidence intervals (CI) are presented for high systolic blood pressure, high fasting blood glucose, high total cholesterol, low HDL cholesterol, high LDL cholesterol, and high triglyceride levels. A p-value lower than 0.05 was considered statistically significant. Statistical analysis was performed by using the SPSS 24.0 software. 


\section{Results}

The final sample involved 5228 non-obese subjects. Out of them, 607 subjects (11.6\%) had abdominal obesity (HWC group), and there were 4621 subjects (88.4\%) with no abdominal obesity (NWC group) (Table 2). Both groups involved more women than men, and the majority of the patients were young (18-29 years) or middle-aged (30-44 years) (Table 2 ).

Table 2 Characteristics of 5228 Hungarian adult subjects the data of who were recorded in the framework of the Swiss-Hungarian Cooperation Programme (2012-2016)

\begin{tabular}{|c|c|c|c|}
\hline Characteristics & HWC group $n(\%)$ & NWC group n (\%) & Total $n(\%)$ \\
\hline$\overline{W C}$ & $607(11.6)$ & $4621(88.4)$ & $5228(100.0)$ \\
\hline \multicolumn{4}{|l|}{ Gender*** } \\
\hline Male & $27(4.4)$ & 2055 (44.5) & $2082(39.8)$ \\
\hline Female & $580(95.6)$ & $2566(55.5)$ & $3146(60.2)$ \\
\hline Total & $607(100.0)$ & $4621(100.0)$ & $5228(100.0)$ \\
\hline \multicolumn{4}{|l|}{$\operatorname{Age}^{* * *}$} \\
\hline $18-29$ & $113(18.6)$ & $1852(40.1)$ & 1965 (37.6) \\
\hline $30-44$ & $166(27.3)$ & $1463(31.7)$ & $1629(31.2)$ \\
\hline $45-59$ & $161(26.5)$ & $866(18.7)$ & 1027 (19.6) \\
\hline $60-74$ & $111(18.3)$ & $323(7.0)$ & $434(8.3)$ \\
\hline$\geq 75$ & $56(9.2)$ & $117(2.5)$ & $173(3.3)$ \\
\hline Total & $607(100.0)$ & $4621(100.0)$ & $5228(100.0)$ \\
\hline \multicolumn{4}{|l|}{ Systolic blood pressure } \\
\hline Normal (< 140 mmHg) & $441(74.2)$ & $3884(85.2)$ & $4325(83.9)$ \\
\hline High ( $\geq 140$ mmHg) & $153(25.8)$ & $675(14.8)$ & $828(16.1)$ \\
\hline Total & $594(100.0)$ & $4559(100.0)$ & $5153(100.0)$ \\
\hline \multicolumn{4}{|l|}{ Fasting blood glucose ${ }^{* *}$} \\
\hline Normal (<6.1 mmol/L) & $448(91.2)$ & $3361(94.3)$ & 3809 (93.9) \\
\hline High ( $\geq 6.1 \mathrm{mmol} / \mathrm{L})$ & $43(8.8)$ & $205(5.7)$ & $248(6.1)$ \\
\hline Total & $491(100.0)$ & $3566(100.0)$ & $4057(100.0)$ \\
\hline \multicolumn{4}{|l|}{ Total cholesterol*** } \\
\hline Normal $(<5.2 \mathrm{mmol} / \mathrm{L})$ & $243(50.3)$ & $2184(62.5)$ & $2427(61.0)$ \\
\hline High ( $\geq 5.2 \mathrm{mmol} / \mathrm{L})$ & $240(49.7)$ & $1313(37.5)$ & $1553(39.0)$ \\
\hline Total & $483(100.0)$ & $3497(100.0)$ & $3980(100.0)$ \\
\hline \multicolumn{4}{|l|}{ HDL cholesterol } \\
\hline Normal ( $\geq 1.0 \mathrm{mmol} / \mathrm{L})$ & $292(95.4)$ & 2356 (95.8) & $2648(95.7)$ \\
\hline Low (< $1.0 \mathrm{mmol} / \mathrm{L})$ & $14(4.6)$ & $104(4.2)$ & $118(4.3)$ \\
\hline Total & $306(100.0)$ & $2460(100.0)$ & $2766(100.0)$ \\
\hline \multicolumn{4}{|l|}{ LDL cholesterol } \\
\hline Normal $(<2.6 \mathrm{mmol} / \mathrm{L})$ & 70 (31.4) & $616(34.3)$ & $686(34.0)$ \\
\hline High ( $\geq 2.6 \mathrm{mmol} / \mathrm{L})$ & $153(68.6)$ & $1181(65.7)$ & $1334(66.0)$ \\
\hline Total & $223(100.0)$ & $1797(100.0)$ & $2020(100.0)$ \\
\hline \multicolumn{4}{|l|}{ Triglyceride** } \\
\hline Normal (< $1.7 \mathrm{mmol} / \mathrm{L})$ & $385(80.2)$ & $2966(85.2)$ & 3351 (84.6) \\
\hline High ( $\geq 1.7 \mathrm{mmol} / \mathrm{L})$ & 95 (19.8) & $514(14.8)$ & 609 (15.4) \\
\hline Total & $480(100.0)$ & $3480(100.0)$ & 3960 (100.0) \\
\hline
\end{tabular}

LDL: low-density lipoprotein; HDL: high-density lipoprotein

NWC: normal WC group with normal weight: WC $\leq 88 \mathrm{~cm}$ and BMI $<25 \mathrm{~kg} / \mathrm{m}^{2}$ in females; and WC $\leq 102 \mathrm{~cm}$ and $\mathrm{BMl}<25 \mathrm{~kg} / \mathrm{m}^{2}$ in males

HWC: high WC group with normal weight: WC $>88 \mathrm{~cm}$ and $\mathrm{BMl}<25 \mathrm{~kg} / \mathrm{m}^{2}$ in females; and WC $>102 \mathrm{~cm}$ and $\mathrm{BMl}<25 \mathrm{~kg} / \mathrm{m}^{2}$ in $\mathrm{males}$

BMI: body mass index; WC: waist circumference

**: $p<0.01 ;{ }^{* * *}: p<0.001$ (Chi-square test of independence) 
Some further data in Table 2 demonstrate that a significantly higher occurrence was found in the HWC group vs the NWC group of high systolic blood pressure $(\mathrm{p}<0.001)$, high fasting blood glucose $(\mathrm{p}=0.009)$, high total cholesterol level $(\mathrm{p}<0.001)$, and high triglyceride levels $(\mathrm{p}=0.004)$. The levels of HDL and LDL cholesterol were not significantly different between the two groups.

The correlation analysis suggested that WC and BMI had a significant correlation $(\mathrm{p}<0.001$ both in males and females). The Pearson's correlation coefficients between WC and BMI were 0.610 in males and 0.526 in females.

According to the results of the multiple logistic regression models, older people had significantly higher odds for developing most of the metabolic risk factors. Subjects in the age group of 30-44 years were significantly more likely to have high systolic blood pressure, high fasting blood glucose, high total cholesterol, and high LDL cholesterol levels compared to the 18-29 year age group (Table 3 ). This significantly increased risk of the occurrence of the above mentioned metabolic risk factors was shown in the older age groups.

An increased risk for high triglyceride level was observed in the 45-59 and 60-74 year old age groups compared to the youngest age group. Subjects in the 45-59 and 60-74 year old age groups had significantly lower odds for low HDL cholesterol. In contrast, the risk increased in the oldest age group, although not significantly (Table 3).

Regarding gender, males had significantly higher odds for having high systolic blood pressure, high fasting blood glucose, low HDL cholesterol, and high triglyceride levels (Table 3).

Subjects in the HWC group were more likely to have some metabolic risk factors compared to those in the NWC group. If a patient had abdominal obesity, the odds for high systolic blood pressure, low HDL cholesterol, and high triglyceride levels increased significantly (Table 3). On the contrary, the risk for high LDL level was lower in the HWC group compared to the NWC group, but it was not significant. The odds of high total cholesterol level was nearly the same in the NWC and the HWC groups (Table 3 ).

\section{Discussion}

In this cross-sectional study, we examined the association of abdominal obesity assessed by WC with the occurrence of metabolic risk factors in non-obese subjects. 5228 subjects were involved in our research, mostly young or middle-aged, and more females than males. Our results showed a high prevalence of abdominal obesity (11.6\%) among non-obese subjects. Our study also presented a very high, positive correlation between BMI and WC, which is consistent with other studies [23, 24].

Subjects with abdominal obesity were proved to have significantly higher prevalence of high systolic blood pressure, high fasting blood glucose, high total cholesterol, and high triglyceride levels than subjects in the NWC group.

Table 3 Odds ratios of metabolic risk factors in the Hungarian subjects with and with no abdominal obesity adjusted for age and gender (multiple logistic regression models, data collected in the framework of the Programme between 2012 and 2016)

\begin{tabular}{|c|c|c|c|c|c|c|}
\hline \multirow[t]{2}{*}{ Characteristics } & $\begin{array}{l}\text { High systolic } \\
\text { blood pressure } \\
(\geq 140 \mathrm{mmHg})\end{array}$ & $\begin{array}{l}\text { High fasting } \\
\text { blood glucose } \\
(\geq 6.1 \mathrm{mmol} / \mathrm{L})\end{array}$ & $\begin{array}{l}\text { High total } \\
\text { cholesterol } \\
(>5.2 \mathrm{mmol} / \mathrm{L})\end{array}$ & $\begin{array}{l}\text { Low HDL } \\
\text { cholesterol } \\
(<1.0 \mathrm{mmol} / \mathrm{L})\end{array}$ & $\begin{array}{l}\text { High LDL } \\
\text { cholesterol } \\
(\geq 2.6 \mathrm{mmol} / \mathrm{L})\end{array}$ & $\begin{array}{l}\text { High triglyceride } \\
(\geq 1.7 \mathrm{mmol} / \mathrm{L})\end{array}$ \\
\hline & OR (95\% Cl) & OR (95\% Cl) & OR $(95 \% \mathrm{Cl})$ & OR $(95 \% \mathrm{Cl})$ & OR $(95 \% \mathrm{Cl})$ & OR $(95 \% \mathrm{Cl})$ \\
\hline \multicolumn{7}{|c|}{ Age (reference: 20-31) } \\
\hline $30-44$ & $2.01(1.55-2.60)^{* * *}$ & $2.36(1.51-3.67)^{* * *}$ & $2.93(2.45-3.50)^{* * *}$ & $0.94(0.61-1.44)$ & $\begin{array}{l}2.98(2.37- \\
3.75)^{* * *}\end{array}$ & $1.20(0.96-1.50)$ \\
\hline $45-59$ & $7.28(5.71-9.28)^{* * *}$ & $5.01(3.27-7.68)^{* * *}$ & $7.35(6.03-8.95)^{* * *}$ & $0.53(0.30-0.94)^{*}$ & $\begin{array}{l}6.55(4.89- \\
8.78)^{* * *}\end{array}$ & $\begin{array}{l}1.51(1.18- \\
1.92)^{* * *}\end{array}$ \\
\hline $60-74$ & $\begin{array}{l}13.56(10.24- \\
17.96)^{* * *}\end{array}$ & $7.78(4.88-12.41)^{* * *}$ & $\begin{array}{l}11.06(8.43- \\
14.50)^{* * *}\end{array}$ & $0.25(0.08-0.80)^{*}$ & $\begin{array}{l}5.44(3.62- \\
8.18)^{* * *}\end{array}$ & $\begin{array}{l}1.78(1.31- \\
2.42)^{* * *}\end{array}$ \\
\hline$\geq 75$ & $\begin{array}{l}22.21(15.32- \\
32.21)^{* * *}\end{array}$ & $\begin{array}{l}10.22(5.82- \\
17.94)^{* * *}\end{array}$ & $6.08(4.23-8.75)^{* * *}$ & $1.17(0.48-2.85)$ & $\begin{array}{l}5.37(2.97- \\
9.73)^{* * *}\end{array}$ & $1.40(0.88-2.24)$ \\
\hline $\begin{array}{l}\text { Gender (reference: } \\
\text { females) }\end{array}$ & $1.97(1.65-2.35)^{* * *}$ & $1.84(1.38-2.45)^{* * *}$ & $0.89(0.77-1.03)$ & $\begin{array}{l}2.89(1.90- \\
4.37)^{* * *}\end{array}$ & $0.92(0.75-1.13)$ & $\begin{array}{l}1.79(1.45- \\
2.16)^{* * *}\end{array}$ \\
\hline $\begin{array}{l}\text { WC (reference: NWC } \\
\text { group) }\end{array}$ & $1.53(1.20-1.94)^{* * *}$ & $1.37(0.93-2.01)$ & $1.02(0.82-1.27)$ & $2.06(1.09-3.89)^{*}$ & $0.75(0.54-1.05)$ & $\begin{array}{l}1.65(1.27- \\
2.16)^{* * * *}\end{array}$ \\
\hline
\end{tabular}

LDL Low-density lipoprotein; HDL High-density lipoprotein

NWC Normal WC group with normal weight: WC $\leq 88 \mathrm{~cm}$ and BMI $<25 \mathrm{~kg} / \mathrm{m}^{2}$ in females; and WC $\leq 102 \mathrm{~cm}$ and BMI $<25 \mathrm{~kg} / \mathrm{m}^{2}$ in males

WC: waist circumference; OR: odds ratio; $\mathbf{C l}$ : confidence interval

Odds ratios were calculated using multiple logistic regression models in which the dependent variable was defined as having metabolic risk factors and it was adjusted for age and gender. The reference group was set as the females and the NWC group

*: $p<0.05 ;{ }^{* * *}: \mathrm{p}<0.001$ 
The risk for having high systolic blood pressure, high fasting blood glucose, high total cholesterol, and high LDL cholesterol levels was age-dependent, these levels were significantly higher in the age group of 30-44 years, and the risk was also significant in the older age groups. In case of high triglyceride level, an increased risk was found in the age groups 45-59 and 60-74 years. In general, as individuals grow older, the body fat content increases, especially in the abdominal region, which may be the cause of the elevated metabolic risk [25]. Therefore, screening of abdominal obesity is crucial in the elderly. Furthermore, males were significantly more affected by most of the cardiometabolic parameters, hence it would be fundamental to measure WC particularly in males. Likewise, the logistic regression model indicated that patients with abdominal obesity had significantly higher odds for high systolic blood pressure, low HDL cholesterol, and high triglyceride levels.

Our results are in line with the findings of other researchers $[26,27]$. In the study of Okosun et al., WC is positively associated with having two or more components of the metabolic syndrome in three ethnic groups in Americans [26]. According to the findings of Huang, WC is a better predictor of insulin resistance [28] and a better predictor of mortality [8] than BMI. Furthermore, a strong association has also been documented between abdominal obesity, CVDs, and total mortality [27].

It is well-known that obesity is strongly related to metabolic, CV, and other diseases [29]. The health risks of abdominal obesity have already been recognized as well, although WC is still less commonly measured than $\mathrm{BMI}$ in the clinical practice [8]. It is of importance that some individuals with normal BMI are insulin resistant and have metabolic abnormalities, which might contribute to an abnormal fat distribution, especially abdominal obesity [30].

It is very important to measure body weight, height, and $\mathrm{WC}$ in a professional and reliable way, for example, during health examinations, as in self-reported health interviews, the subjects tend to underestimate their weight and/or overestimate body height [31].

Obviously, there are differences in the recommendations regarding the screening of obesity in the world. The Obesity Society Guidelines (2013) for Managing Overweight and Obesity in Adults do not recommend measuring the WC [32]. The U.S. Preventive Services Task Force (USPSTF) recommends the screening of all adults for obesity by the calculation of the BMI, although it also states that WC may be an acceptable alternative to BMI measurement in some patient subpopulations [33]. Nonetheless, Hungary has adapted the available evidence that measurement of WC is effective in the prevention of cardiometabolic disorders; thus, according to a decree [34] regarding screenings done by
GPs and financed by the health insurance, measurement of WC is to be included in the physical examination over 21 years of age, and it should be repeated every 5 years. Despite the existing legal support for screenings in primary health care, the cardiometabolic preventive services are used at much lower rates than recommended for the age group of 21-64 years, and it might contribute to the extremely high CV mortality in Hungary [35]. In a study performed in a relatively large sample (3121 subjects), cardiometabolic risk has been assessed in only $44.45 \%$ of the individuals [36].

The logistic regression model also showed that the risk for elevated LDL cholesterol level was lower in patients with abdominal obesity. This is consistent with a study [37] in which it was found that high LDL cholesterol remained relatively unchanged with inreased WC. Possibly, the LDL cholesterol level was modified by cholesterol-lowering therapy, which primarily aims to decrease LDL cholesterol level (it is one of the known limitations, see below).

Using the BMI alone to identify metabolic risks, several patients with increased risk but normal BMI would be missed. To measure $\mathrm{WC}$ is particularly important above 30 years of age and in males, irrespective of their BMI.

The strengths of our study were the large sample size, the measurement of WC by trained health personnel, and the interpretation of the results of a new, innovative model programme in terms of screening in primary care in Hungary.

Our limitations involve that the study was not representative (selection bias), and we could not determine cause-and-effect relationships due to the cross-sectional type of this study.

Finally, not all laboratory parameters were available for each subject. In this analysis, we applied the definition of ATP III to classify the patient as having abdominal obesity (but data were not analyzed according to International Diabetes Federation (IDF) thresholds). As we did not have information on which patients had cholesterol lowering therapy, we could not exclude them from the present analysis, although this therapy might modify the measured LDL cholesterol levels and model calculations based on them.

\section{Conclusions}

Our results suggest that screening of abdominal obesity by applying a simple, professionally performed measurement of WC might be a suitable predictor of metabolic syndrome, potentially more practical than, e.g., BMI.

The prevention of metabolic syndrome and the possible outcomes, such as CVDs and diabetes, would be especially beneficial in the Hungarian population, where CVDs are the leading causes of death, and the morbidity of T2DM is continuously increasing. 


\section{Supplementary information}

Supplementary information accompanies this paper at https://doi.org/10. 1186/s12889-019-7839-1

Additional file 1: Table S1. Characteristics of 12,520 Hungarian adult subjects - the data of who were recorded in the framework of the Swiss-Hungarian Cooperation Programme (2012-2016).

Additional file 2. The data collected and the questions applied in the HSA.

\section{Abbreviations}

ATP III: Adult Treatment Panel III; BMI: Body mass index; Cl: 95\% confidence interval; COPD: Chronic obstructive pulmonary disease; CVD: Cardiovascular disease; GPC: General practitioners' cluster; HDL: High density lipoprotein; HSA: Health status assessment; HWC: High waist circumference; IDF: International Diabetes Federation; LDL: low density lipoprotein; NCEP: National Cholesterol Education Program; NWC: Normal waist circumference; OR: Odds ratios; SPSS: Statistical Package for the Social Sciences; T2DM: Type 2 diabetes mellitus; USPSTF: United States Preventive Services Task Force; WC: Waist circumference; WHO: World Health Organization

\section{Acknowledgements}

Not applicable.

\section{Authors' contributions}

JS, RÁ, and MP took leadership and responsibility for the research activity planning and made substantial contributions to the conception and design of the Programme. KV worked on the statistical analysis of the data. $A L, E H$, $A S z$, and ZsM carried out the interpretation of the results. EP drafted the concept of the paper as well as participated in finalizing the manuscript. All authors read and approved the final manuscript.

\section{Funding}

The reported study was conducted in the framework of the "Public Health Focused Model Programme for Organising Primary Care Services Backed by a Virtual Care Service Centre" (SH/8/1). The Model Programme (the planning and design of the study, data collection, analysis and interpretation) has been funded by the Swiss Government via the Swiss Contribution Programme $(\mathrm{SH} / 8 / 1)$ in agreement with the Government of Hungary, but the funding body had no influence on the professional content of the Programme.

\section{Availability of data and materials}

The datasets used and/or analysed during the current study are available from the corresponding author on reasonable request.

\section{Ethics approval and consent to participate}

The study protocol was approved by the Scientific and Research Committee of the Medical Research Council (ETT-TUKEB) (approval reference number: 52119-2/2015 EKU). All subjects signed an informed consent form, and the anonymity of personal information was guaranteed during data analysis.

\section{Consent for publication}

Not applicable.

\section{Competing interests}

The authors declare that they have no competing interests.

\section{Author details}

'Department of Public Health, Faculty of Medicine, University of Szeged, Dóm tér 10, Szeged 6720, Hungary. ${ }^{2}$ Department of Medical Physics and Informatics, University of Szeged, Szeged, Hungary. ${ }^{3}$ National Public Health Center, Budapest, Hungary. ${ }^{4}$ Department of Preventive Medicine, Faculty of Public Health, University of Debrecen, Debrecen, Hungary. ${ }^{5}$ MTA-DE Public Health Research Group, Department of Preventive Medicine, Faculty of Public Health, University of Debrecen, Debrecen, Hungary.
Received: 31 May 2019 Accepted: 24 October 2019

Published online: 15 November 2019

\section{References}

1. Blüher M. Obesity: global epidemiology and pathogenesis. Nat Rev Endocrinol. 2019;15(5):288-98.

2. N. C. D. Risk Factor Collaboration: Worldwide trends in body-mass index, underweight, overweight, and obesity from 1975 to 2016: a pooled analysis of 2416 population-based measurement studies in 128.9 million children, adolescents, and adults. Lancet. 2017;390(10113):2627-42.

3. Organisation for Economic Co-operation and Development. Obesity update 2017. OECD https://www.oecd.org/els/health-systems/Obesity-Update-2017. pdf. Accessed 20 May 2018.

4. Rurik I, Ungvári T, Szidor J, Torzsa P. Móczár Cs, Jancsó Z, Sándor J. Obese Hungary. Trend and prevalence of overweight and obesity in Hungary, 2015. Orv. Hetil. 2016;157(31):1248-55.

5. Li W, Wang D, Wang X, Gong Y, Cao S, Yin X, Zhuang X, Shi W, Wang Z, Lu $Z$. The association of metabolic syndrome components and diabetes mellitus: evidence from China National Stroke Screening and Prevention Project. BMC Public Health. 2019;19(1):192.

6. Erdei G, Kovács VA, Bakacs M, Martos É. Hungarian Diet and Nutritional Status Survey 2014. I. Nutritional status of the Hungarian adult population. Orv Hetil. 2017;158(14):533-40.

7. Domján BA, Ferencz V, Tänczer T, Szili-Janicsek Z, Barkai L, Hidvégi T, et al. Large increase in the prevalence of self-reported diabetes based on a nationally representative survey in Hungary. Prim Care Diabetes. 2017:11(2):107-11.

8. World Health Organization. Waist Circumference and Waist-Hip Ratio. Report of a WHO Consultation. Geneva: World Health Organization (2008) http:// apps.who.int/iris/bitstream/10665/44583/1/9789241501491_eng.pdf Accessed: 20 May 2018.

9. Hsieh SD, Yoshinaga H, Muto T. Waist-to-height ratio, a simple and practical index for assessing central fat distribution and metabolic risk in Japanese men and women. Int J Obes Relat Metab Disord. 2003;27(5):610-6.

10. Park J, Lee ES, Lee DY, Kim J, Park SE, Park CY, et al. Waist circumference as a marker of obesity is more predictive of coronary artery calcification than body mass index in apparently healthy Korean adults: The Kangbuk Samsung Health Study. Endocrinol Metab. 2016:31:559-66.

11. Lee SC, Hairi NN, Moy FM. Metabolic syndrome among non-obese adults in the teaching profession in Melaka. Malaysia. J Epidemiol. 2017;27(3):130-4.

12. Thaikruea $L$, Thammasarot J. Prevalence of normal weight central obesity among Thai healthcare providers and their association with CVD risk: a cross-sectional study. Sci Rep. 2016;6:37100.

13. Czernichow S, Kengne AP, Stamatakis E, Hamer M, Batty GD. Body mass index, waist circumference and waist-hip ratio: which is the better discriminator of cardiovascular disease mortality risk? Evidence from an individual-participant meta-analysis of 82864 participants from nine cohort studies. Obes Rev. 2011;12(9):680-7.

14. Sándor J, Kósa K, Fürjes G, Papp M, Csordás Á, Rurik I, et al. Public health services provided in the framework of general practitioners' clusters. Eur J Public Health. 2013;23(4):530-2.

15. Sándor J, Kósa K, Papp M, Fürjes G, Körösi L, Jakovljevic M, et al. CapitationBased Financing hampers the Provision of Preventive services in Primary health care. Front Public Health. 2016;4:200.

16. Ádány R, Kósa K, Sándor J, Papp M, Fürjes G. General practitioners' cluster: a model to reorient primary health care to public health services. Eur J Public Health. 2013;23(4):529-30.

17. Adány R. Operations manual for GPs' cluster on public health services in primary health care. Version 05. (2013) https://nepegeszseg.hu/Swiss/SH.8.1_ operations manual version5.pdf Accessed: 20 May 2018.

18. Third Report of the National Cholesterol Education Program Expert Panel on Detection, Evaluation, and Treatment of High Blood Cholesterol in Adults (Adult Treatment Panel III). National Institutes of health. National heart, lung and blood institute; 2002. https://www.nhlbi.nih.gov/files/docs/resources/ heart/atp-3-cholesterol-full-report.pdf. Accessed 20 May 2018.

19. Definition, Diagnosis and Classification of Diabetes Mellitus and its Complications. Report of a WHO Consultation. (1999) http://apps.who. int/iris/bitstream/10665/66040/1/WHO_NCD_NCS_99.2.pdf Accessed: 20 May 2018.

20. STEPwise approach to surveillance (STEPS). Geneva, World Health Organization (WHO), (2008) http://www.who.int/chp/steps/2007_Report StKitts.pdf Accessed: 20 May 2018. 
21. Obesity: Preventing and managing the global epidemic. Report of a WHO Consultation. World Health Organization Geneva 2000. (WHO Technical Report Series, No. 894). http://apps.who.int/iris/handle/10665/42330 Accessed: 20 May 2018.

22. American Heart Association. Understanding and Managing High Blood Pressure. (2014) https://www.heart.org/idc/groups/heart-public/@wcm/ @hcm/documents/downloadable/ucm_461840.pdf Accessed: 15 June 2018.

23. Hu L, Huang X, You C, Li J, Hong K, Li P, Wu Y, Wu Q, Wang Z, Gao R, Bao $\mathrm{H}$, Cheng X. Prevalence of overweight, obesity, abdominal obesity and obesity-related risk factors in southern China. PLoS One. 2017;12(9): e0183934

24. Chinedu SN, Ogunlana OO, Azuh DE, Iweala EE, Afolabi IS, Uhuegbu CC, Idachaba ME, Osamor VC. Correlation between body mass index and waist circumference in Nigerian adults: implication as indicators of health status. J Public Health Res. 2013;2(2):e16.

25. Atlantis E, Martin SA, Haren MT, Taylor AW, Wittert GA. Lifestyle factors associated with age-related differences in body composition: the Florey Adelaide Male Aging Study. Am J Clin Nutr. 2008;88:95-104.

26. Okosun IS, Liao Y, Rotimi CN, Prewitt TE, Cooper RS. Abdominal adiposity and clustering of multiple metabolic syndrome in white, black and hispanic Americans. Ann Epidemiol. 2000;10(5):263-70.

27. Cerhan JR, Moore SC, Jacobs EJ, Kitahara CM, Rosenberg PS, Adami HO, et al. A pooled analysis of waist circumference and mortality in 650,000 adults. Mayo Clin Proc. 2014;89(3):335-45.

28. Huang L-H, Liao Y-L, Hsu C-H. Waist circumference is a better predictor than body mass index of insulin resistance in type 2 diabetes. Obes Res Clin Pract. 2012;6(4):314-20.

29. Pi-Sunyer X. The Medical Risks of Obesity. Postgrad Med. 2009;121(6):21-33. Orces $\mathrm{CH}$, Montalvanb M, Tettamantic D: Prevalence of abdominal obesity and its association with cardio metabolic risk factors among older adults in Ecuador. Diabetes Metab Syndr. 2017;11(2):727-33.

30. Kaur J. Assessment and screening of the risk factors in metabolic syndrome. Med Sc. 2014;2:140-52.

31. 2013 AHA/ACC/TOS Guideline for the Management of Overweight and Obesity in Adults. A Report of the American College of Cardiology/ American Heart Association. Task Force on Practice Guidelines and The Obesity Society. https:/www.ncbi.nlm.nih.gov/pmc/articles/PMC5819889/ pdf/nihms936584.pdf. Accessed 20 May 2018.

32. Health at a Glance 2015. OECD Indicators. Published by OECD in 2015 . http://apps.who.int/medicinedocs/documents/s22177en/s22177en.pdf Accessed: 20 May 2018.

33. Virginia A. Moyer: Screening for and Management of Obesity in Adults: U.S. Preventive Services Task Force Recommendation Statement. Ann Intern Med. 2012;157:373-8.

34. Decree No. 51/1997 of the Minister of Welfare on compulsory health insurance-based health services that are aimed to prevent and timely detect these diseases and on the certification of screenings. (in Hungarian) http://net.jogtar.hu/jogszabaly?docid=99700051.nm Accessed: 25 July 2018

35. Hungarian Central Statistical Office: Changing in mortality patterns and causes of death in Hungary, 2000-2012. Budapest (2014) (in Hungarian) https://www.ksh.hu/docs/hun/xftp/idoszaki/pdf/halalokistruk.pdf Accessed: 20 May 2018.

36. Sándor J, Nagy A, Földvári A, Szabó E, Csenteri O, Vincze F, Sipos V, Kovács N, Pálinkás A, Papp M, Fürjes G, Ádány R. Delivery of cardio-metabolic preventive services to Hungarian Roma of different socio-economic strata. Fam Pract. 2017;34(1):83-9.

37. Orces $\mathrm{CH}$, Montalvanb M, Tettamantic D. Prevalence of abdominal obesity and its association with cardio metabolic risk factors among older adults in Ecuador. Diabetes Metab Syndr. 2017;11(2):727-33.

\section{Publisher's Note}

Springer Nature remains neutral with regard to jurisdictional claims in published maps and institutional affiliations.

Ready to submit your research? Choose BMC and benefit from:

- fast, convenient online submission

- thorough peer review by experienced researchers in your field

- rapid publication on acceptance

- support for research data, including large and complex data types

- gold Open Access which fosters wider collaboration and increased citations

- maximum visibility for your research: over $100 \mathrm{M}$ website views per year

At $\mathrm{BMC}$, research is always in progress.

Learn more biomedcentral.com/submissions 